\title{
Immediate versus secondary DIEP flap breast reconstruction: a multicenter outcome study
}

\author{
L. Prantl ${ }^{1} \cdot$ N. Moellhoff ${ }^{2} \cdot$ U. von Fritschen ${ }^{3} \cdot$ R. E. Giunta ${ }^{2} \cdot$ G. Germann ${ }^{4} \cdot$ A. Kehrer ${ }^{1}$ - D. Lonic ${ }^{1} \cdot$ F. Zeman ${ }^{5}$. \\ P. N. Broer ${ }^{6}$ P. I. Heidekrueger ${ }^{1}$ (1)
}

Received: 18 June 2020 / Accepted: 28 August 2020 / Published online: 7 September 2020

(c) The Author(s) 2020

\begin{abstract}
Purpose Immediate breast reconstruction (IBR) at the time of mastectomy is gaining popularity, as studies show no negative impact on recurrence or patient survival, but better aesthetic outcome, less psychological distress and lower treatment costs. Using the largest database available in Europe, the presented study compared outcomes and complications of IBR vs. delayed breast reconstruction (DBR).

Methods 3926 female patients underwent 4577 free DIEP-flap breast reconstructions after malignancies in 22 different German breast cancer centers. The cases were divided into two groups according to the time of reconstruction: an IBR and a DBR group. Surgical complications were accounted for and the groups were then compared.

Results Overall, the rate of partial-(1.0 versus 1.2 percent of cases; $p=0.706)$ and total flap loss (2.3 versus 1.9 percent of cases; $p=0.516$ ) showed no significant difference between the groups. The rate of revision surgery was slightly, but significantly lower in the IBR group ( 7.7 versus 9.8 percent; $p=0.039$ ). Postoperative mobilization was commenced significantly earlier in the IBR group (mobilization on postoperative day 1: 82.1 versus 68.7 percent; $p<0.001$ ), and concordantly the mean length of hospital stay was significantly shorter (7.3 (SD3.7) versus 8.9 (SD13.0) days; $p<0.001$ ).

Conclusion IBR is feasible and cannot be considered a risk factor for complications or flap outcome. Our results support the current trend towards an increasing number of IBR. Especially in times of economic pressure in health care, the importance of a decrease of hospitalization cannot be overemphasized.
\end{abstract}

Keywords Breast reconstruction · DIEP flap · Immediate breast reconstruction · Delayed breast reconstruction · Microsurgery

L. Prantl and N. Moellhoff have contributed equally to the preparation of the manuscript.

P. I. Heidekrueger paul@heidekrueger.net

1 Centre of Plastic, Aesthetic, Hand and Reconstructive Surgery, University of Regensburg, Franz-Josef-Strauß-Allee 11, 93053 Regensburg, Germany

2 Division of Hand, Plastic and Aesthetic Surgery, University Hospital, LMU Munich, Munich, Germany

3 Department of Plastic and Esthetic Surgery, Hand Surgery, Helios Hospital Emil von Behring, Berlin, Germany

4 Department of Plastic, Reconstructive, Esthetic and Handsurgery, ETHIANUM Klinik, Heidelberg, Germany

5 Center for Clinical Studies, University Medical Center Regensburg, Regensburg, Germany

6 Department of Plastic, Reconstructive, Hand and Burn Surgery, Bogenhausen Academic Teaching Hospital, Munich, Germany

\section{Introduction}

Breast reconstruction is an integral part of holistic breast cancer treatment. It lessens the profound impact that breast cancer diagnosis and therapy have on patients psyche [1] and thus constitutes to an increase of quality of life, social participation and improved self-esteem [2-5].

Several reconstructive approaches exist [6]. Currently, immediate breast reconstruction (IBR) at the time of mastectomy is gaining popularity $[7,8]$. Studies show that IBR has no negative impact on recurrence or patient survival, even in patients with advanced disease $[9,10]$.

For various reasons, implant-based techniques are used for a majority of patients that receive IBR $[8,11]$. However, outcome research suggests that autologous tissue transfer shows superior long-term satisfaction, more stable aesthetic results and higher quality of life [12-14]. To this end, the 
free deep inferior epigastric artery perforator-(DIEP) flap has proven to be a working horse for autologous breast reconstruction $[15,16]$.

Immediate and delayed breast reconstruction (DBR) have been compared with regard to complication rates and clinical outcomes. Reports show better aesthetic outcome, less psychological distress and lower treatment costs following IBR $[6,17,18]$. However, most studies focus on comparing autologous with implant-based reconstructions [6-8, 11], or immediate and delayed autologous reconstructions in women who require post-mastectomy radiation therapy (PMRT) $[19,20]$. To date, there is a paucity of significant data on overall complications after immediate versus delayed autologous flap reconstruction. To our knowledge, the largest series compared 910 DIEP flaps in a multicenter retrospective cohort study, including merely 397 cases of IBR [21].

To shed further light onto this topic, we performed a comprehensive analysis of 4577 DIEP free flap breast reconstructions at 22 different German breast cancer centers and compared outcomes and complications after IBR vs. DBR.

\section{Materials/patients and methods}

\section{Design of the online registry}

The German Society of Plastic, Reconstructive and Aesthetic Surgeons (DGPRÄC) initiated a prospective online registry in 2011, to present the structure and quality of free flap breast reconstructions in Germany [22]. Details with regard to the registry and the plastic surgical centers involved have been previously published by Fritschen et al. [22]. In short, plastic surgical centers were certified by the DGPRÄC, before data entry. Ethical approval was obtained from the ethics commission of the Bavarian State Medical Association (156/17 S) and the Berlin Chamber of Physicians (Eth-V-Q/17) prior to initiation of the registry. Data of free flap breast reconstructions were entered intraoperatively, or immediately postoperatively, in a prospective manner and included patients' demographics, patients' characteristics, perioperative details, postoperative complications and free flap outcome. Follow-up data of free flap outcome were entered for 3 months postoperatively in the database. Centers were audited and monitored with regard to the quality and stringency of the data entered in comparison with the hospital's internal documentation [22]. Parts of this database have been previously evaluated by our study group [23].

\section{Collection of data}

22 centers performed DIEP flap reconstructions between January 2011 and January 2019. Data of a total of 3926 female patients, that underwent 4577 free DIEP-flap breast reconstructions, were included in this study. The study included only women that received uni- or bilateral DIEP flap breast reconstruction due to breast cancer. 629 Patients received simultaneous bilateral DIEP-flap reconstruction. If contralateral reconstruction was achieved using a different flap type, we only included the DIEP flap in the study. "Salvage" DIEP flaps performed for women with complications after reconstruction using other free flaps or implant-based reconstructions (e.g., infection, extrusion, or severe pain/cosmetic failure caused by capsule formation) were also included in this study. To analyze a uniform group of patients, women that received breast reconstruction using a different reconstructive approach (i.e., muscle-sparing transverse rectus abdominis-(msTRAM)) were excluded from the study. Other than that, there were no distinct exclusion criteria. However, a complete dataset for every patient to be included was mandatory. The completeness of inclusion was verified by an auditing team. The cases were divided into two groups according to the time of reconstruction: an IBR and a DBR group. Surgical complications were accounted for and the groups were then compared. Clinical outcome analysis was performed by plastic surgeons at the individual centers. The outcomes investigated included total flap loss, partial flap loss, unexpected or emergent revision surgery and reasons for revision surgery (arterial and venous thrombosis, surgical site infection, hematoma donor or recipient site), wound healing disturbances and any medical complications (i.e., deep vein thrombosis, pulmonary embolism, myocardial infarct and others) that occurred postoperatively.

\section{Statistical analysis}

Sample size: No a priori sample size calculation was performed for this study for two reasons. The expected number of patients in the chosen time interval was high enough for detection of any clinically relevant difference without having the risk of being under powered. There was no primary endpoint for a sample size calculation, since this is an exploratory trial with several different endpoints.

Statistical methods: Data are shown as mean (standard deviation) or as absolute and relative frequencies. A $t$-test or a Chi squared test of independence was used to determine differences between groups. Results were considered statistically significant at a probability level of $\leq 0.05$ to guide conclusions. All analyses were performed using SAS (Version 9.4, The SAS institute, Cary, NC). 


\section{Results}

\section{Demographics and patient characteristics}

Patients' characteristics are shown in Table 1. The IBR group included 897 patients (1136 free flaps, mean age 49.9 years (SD 11.5)) and the DBR group included 3016 patients (3441 free flaps, mean age 51.8 years (SD 35.8)).

Preoperative evaluation revealed no significant differences regarding perioperative risk factors such as BMI, comorbidities (diabetes mellitus, coagulopathy), or smoking

Table 1 Patient characteristics

\begin{tabular}{|c|c|c|c|}
\hline Patient characteristics & $\begin{array}{l}\text { Immediate } \\
\text { reconstruction }\end{array}$ & Delayed reconstruction & $p$ value \\
\hline Patients, $n$ & 897 & 3016 & \\
\hline Free flaps, $n$ & 1136 & 3441 & \\
\hline \multicolumn{4}{|l|}{ Age, years } \\
\hline Mean (SD) & $49.9(11.5)$ & $51.8(35.8)$ & 0.082 \\
\hline \multicolumn{4}{|l|}{ BMI, $\mathrm{kg} / \mathrm{m}^{2}$} \\
\hline Mean (SD) & $26.2(4.8)$ & $26.3(4.3)$ & 0.733 \\
\hline Smoking history, $n(\%)$ & $106(9.3)$ & $370(10.8)$ & 0.192 \\
\hline \multicolumn{4}{|l|}{ Comorbidities, $n(\%)$} \\
\hline Diabetes mellitus & $32(2.8)$ & $93(2.7)$ & 0.921 \\
\hline Coagulopathy $^{\mathrm{a}}$ & $15(1.3)$ & $56(1.6)$ & 0.557 \\
\hline Abdominal scar $>10 \mathrm{~cm}, n(\%)$ & $27(2.4)$ & $165(4.8)$ & 0.001 \\
\hline $\begin{array}{l}\text { Family history of breast and/or ovarian cancer } \\
\text { in FDRs, } n(\%)\end{array}$ & $346(30.5)$ & 845 (24.6) & $<0.001$ \\
\hline Genetic disposition, $n(\%)^{\mathrm{b}}$ & $254(22.4)$ & 443 (12.9) & $<0.001$ \\
\hline Chemotherapy within last 6 months, $n(\%)^{\mathrm{c}}$ & $426(37.5)$ & $2179(63.3)$ & $<0.001$ \\
\hline Chemotherapy later than 6 months, $n(\%)^{\mathrm{d}}$ & 243 (21.4) & $1963(57.0)$ & $<0.001$ \\
\hline Immunosuppressive therapy, $n(\%)^{\mathrm{e}}$ & $6(0.5)$ & $28(0.8)$ & 0.44 \\
\hline Tamoxifen therapy, $n(\%)^{\mathrm{f}}$ & $101(8.9)$ & $383(11.1)$ & 0.038 \\
\hline Neoadjuvant radiation therapy, $n(\%)$ & $209(18.5)$ & $1433(41.6)$ & $<0.001$ \\
\hline Indication, $n(\%)$ & & & $<0.001$ \\
\hline Status after mastectomy & $22(2.0)$ & $1533(56.3)$ & \\
\hline DCIS & $139(12.4)$ & $41(1.5)$ & \\
\hline Primary carcinoma & $381(34.0)$ & $55(2.0)$ & \\
\hline Familial risk ${ }^{\mathrm{g}}$ & $223(19.9)$ & $39(1.4)$ & \\
\hline Complications after other reconstruction ${ }^{\mathrm{h}}$ & $12(1.1)$ & $801(29.4)$ & \\
\hline Benign tumor & $26(2.3)$ & $21(0.8)$ & \\
\hline Status after BCT & $193(17.2)$ & $128(4.7)$ & \\
\hline Tumor recurrence & $92(8.2)$ & $30(1.1)$ & \\
\hline Other & $31(2.8)$ & $74(2.7)$ & \\
\hline
\end{tabular}

Comparison of patients' demographics, comorbidities, risk factors for breast cancer, systemic breast cancer treatment and reasons (indication) for DIEP flap reconstruction. Percentages for each item were calculated based on the number of free flaps in each group

n, number; SD, standard deviation; BMI, Body Mass Index; FDR, first degree relatives; BCT, Breast-Conserving Therapy; DCIS, Ductal Carcinoma in Situ

${ }^{\text {a }}$ Self-reported clinical history of any derangement of hemostasis resulting in impaired clot formation

${ }^{b}$ No positive test but a positive family history for breast cancer

${ }^{\mathrm{c}}$ Neoadjuvant Chemotherapy within the last 6 months prior to breast reconstruction

${ }^{\mathrm{d}}$ Neoadjuvant Chemotherapy more than 6 months prior to breast reconstruction

${ }^{\mathrm{e}}$ Immunotherapy using targeted antibodies for tumors that overexpress HER-2 protein receptor

${ }^{\mathrm{f}}$ Patients with hormone-receptor positive breast cancer receiving tamoxifen therapy

$\mathrm{g}_{\text {i.e., }}$ risk-reducing mastectomy due to pathogenic mutation identified in genetic test for familial/hereditary breast cancer

${ }^{\mathrm{h}}$ Complications after previous reconstructive procedure (i.e., implant reconstruction) 
history $(p>0.05)$. Merely, a significantly higher prevalence of abdominal scars was observed (4.8 percent versus 2.4 percent; $p=0.001)$ in the DBR group.

Risk factors for breast cancer, such as a positive family history of breast and/or ovarian cancer in first degree relatives (FDRs) (30.5 versus 24.6 percent of cases; $p<0.001$ ) and genetic disposition (22.4 versus 12.9 percent of cases; $p<0.001$ ) were significantly higher in the IBR group.

With regard to systemic breast cancer therapy, neoadjuvant chemotherapy was administered significantly more frequently in the IBR group (within 6 months prior to reconstruction: 37.5 versus 63.3 percent of cases, $p<0.001$; more than 6 months prior to reconstruction: 21.4 versus 57.0 percent of cases, $p<0.001)$. Conversely, patients in the DBR group received Tamoxifen therapy significantly more frequently (8.9 versus 11.1 percent of cases; $p=0.038$ ). Immunotherapy using targeted antibodies was comparable between both groups $(p>0.05)$. A significantly lower number of patients in the IBR group received neoadjuvant radiation therapy (18.5 versus 41.6 percent of cases; $p<0.001$ ).

The indication for DIEP flap reconstructions differed significantly between the groups $(p<0.001)$. Indications for patients in the IBR group predominantly included primary carcinoma (34.0 percent), familial risk (19.9 percent), or ductal carcinoma in situ (DCIS, 12.4 percent), whereas most patients of the DBR group required reconstruction after mastectomy ( 56.3 percent) or due to a complication after an unsuccessful other type of breast reconstruction (29.4 percent).

\section{Perioperative details and postoperative complications}

All perioperative characteristics are summarized in Table 2. Mean ischemia time was significantly shorter in the IBR group (44 (SD26.1) versus 53 min (SD25.4); $p<0.001$ ), whereas mean operative time did not differ significantly (315 (SD144.6) versus 320 (SD121.9) minutes; $p=0.29$ ).

Mean length of hospital stay was significantly shorter in the IBR group (7.3 (SD3.7) versus 8.9 (SD13.0) days; $p<0.001)$. Postoperative mobilization started significantly earlier in the IBR group (mobilization on postoperative day 1: 82.1 versus 68.7 percent; $p<0.001$ ).

Postoperative complications are displayed in Table 3. Overall, there was no significant difference between the groups of patients regarding the rate of partial (1.0 versus 1.2 percent of cases; $p=0.706$ ) and total flap loss ( 2.3 versus 1.9 percent of cases; $p=0.516$ ). Revision rates were slightly, but significantly lower in the IBR group ( 7.7 versus 9.8 percent; $p=0.039$ ). When analyzing reasons for revision surgery, we found that the rate of hematomas at the recipient site was significantly lower in the IBR group (2.2 versus 3.6 percent; $p=0.03$ ).
The prevalence of medical complications was comparable between both groups ( 6.6 versus 6.4 percent; $p=0.777$ ) (Table 3).

\section{Discussion}

Immediate breast reconstruction has become the preferred reconstructive approach for women with breast cancer. According to the literature, more than $70 \%$ of breast reconstructions are performed at the time of mastectomy [6], for several reasons. Studies have shown that IBR is oncologically safe [24-26]. The introduction of skin-sparing and nipple-sparing mastectomy has allowed immediate breast reconstruction to gain momentum [27]. Here, the native breast skin envelope remains intact, which facilitates good aesthetic results, especially for microvascular autologous tissue-based reconstructions [28-30]. Psychologically, patients receiving IBR show less anxiety or depression and higher levels of self-esteem, sexuality and an increased quality of life $[4,31,32]$.

As stated previously, most IBRs are implant-based reconstructions $[8,11,27]$. Several studies provide an explanation for this phenomenon. Exemplary, while physician payments for prosthetic reconstruction have risen over the past years, there is a stagnation in compensation for autologous reconstruction. In addition, there is a significant opportunity cost related to autologous breast reconstruction due to high physician effort, long operative hours and extended hospitalization [33-35]. Nevertheless, autologous tissue transfer shows superior long-term results [12-14]. Prior studies have compared overall outcome and complications of immediate and delayed breast reconstructions, mostly, however, without differentiating between autologous and prosthetic reconstruction and producing inconsistent conclusions with regard to an increase of complications in either group [6, 36-39].

Hence, this study aimed at generating a distinguished analysis for DIEP-flaps, the commonly preferred approach for autologous breast reconstruction $[15,16]$. Based on the largest patient series to date, the presented study compared the outcomes of 4577 DIEP free flap reconstructions with regard to the timing of reconstruction. Overall, we found no significant difference in the rate of total or partial flap loss when comparing IBR with DBR. In this regard, our data agree with a recent study of Beugels et al. who also describe no significant differences in major complications or flap re-explorations between immediate and delayed reconstructions [21]. Conversely, they found significantly more hematomas in immediate reconstructions and a higher rate of wound healing disturbances in delayed reconstructions [21], which is not supported by our data. Our data show a slightly, but significantly higher rate of revision surgery in DBRs which can be attributed to a 
Table 2 Perioperative details according to timing of reconstruction

\begin{tabular}{|c|c|c|c|}
\hline Perioperative details & $\begin{array}{l}\text { Immediate recon- } \\
\text { struction }\end{array}$ & Delayed reconstruction & $p$ value \\
\hline Free flaps, $n$ & 1136 & 3441 & \\
\hline Reconstructed side, $n(\%)$ & & & $<0.001$ \\
\hline Right & $322(28.3)$ & $1238(36.0)$ & \\
\hline Left & $344(30.3)$ & $1332(38.7)$ & \\
\hline Both & $470(41.4)$ & $871(25.3)$ & \\
\hline \multicolumn{4}{|l|}{ Operation time, $\min$} \\
\hline Mean (SD) & $315(144.6)$ & $320(121.9)$ & 0.29 \\
\hline \multicolumn{4}{|l|}{ Ischemia time, $\min$} \\
\hline Mean (SD) & $44(26.1)$ & $53(25.4)$ & $<0.001$ \\
\hline \multicolumn{4}{|l|}{ Recipient vessels, $n(\%)$} \\
\hline Internal mammary & $958(84.3)$ & $2725(79.2)$ & 0.002 \\
\hline Thoracodorsal & $142(12.5)$ & $562(16.3)$ & 0.002 \\
\hline Other & $36(3.2)$ & $154(4.5)$ & 0.056 \\
\hline \multicolumn{4}{|l|}{ Flap monitoring, $n(\%)$} \\
\hline Clinically & $1119(98.5)$ & $3409(99.1)$ & 0.149 \\
\hline Transcutaneous doppler probe & $219(19.3)$ & $1827(53.1)$ & $<0.001$ \\
\hline Perivascular doppler probe (i.e., cook) & $0(0.0)$ & $26(0.8)$ & 0.007 \\
\hline Transcutaneous $\mathrm{HbO} 2$ test (i.e., $\mathrm{O} 2 \mathrm{C}$ ) & $0(0.0)$ & $10(0.3)$ & 0.146 \\
\hline Warm touch preoperatively & $76(6.7)$ & $146(4.2)$ & 0.001 \\
\hline Warm touch postoperatively & $719(63.3)$ & $1644(47.8)$ & $<0.001$ \\
\hline \multicolumn{4}{|l|}{ Postoperative mobilization, $n(\%)$} \\
\hline Postop day 1 & $933(82.1)$ & $2360(68.7)$ & $<0.001$ \\
\hline Postop day 2 & $95(8.4)$ & $678(19.7)$ & \\
\hline Postop day 3 & $21(1.8)$ & $105(3.1)$ & \\
\hline Postop day 4 & $58(5.1)$ & $108(3.1)$ & \\
\hline Postop day 5 & $17(1.5)$ & $81(2.4)$ & \\
\hline Postop day 6 & $11(1.0)$ & $61(1.8)$ & \\
\hline Postop day 7 & $1(0.1)$ & $41(1.2)$ & \\
\hline \multicolumn{4}{|l|}{ Hospital stay, days } \\
\hline Mean (SD) & $7.3(3.7)$ & $8.9(13.0)$ & $<0.001$ \\
\hline
\end{tabular}

Percentages for each item are calculated based on the number of free flaps in each group $\mathrm{n}$, number; SD, standard deviation; min, minutes significantly higher rate of hematomas at the recipient site in this group. Operating in scarred and fibrous tissue, as is the case in many DBR patients that received neoadjuvant radiation and mastectomy, may cause higher rates of hematoma and thus also higher surgical revision rates [40].

According to Fischer et al. autologous IBR adds a significant risk for venous thromboembolism, including deep venous thrombosis and pulmonary embolism [37]. Contrary, in our investigated group of DIEP-flap reconstructions, this finding did not hold true. Instead, our results show that postoperative medical complications were comparable between both groups and rates of venous flap thrombosis were similar.

While mean ischemia time was longer in the DBR group, operative times in total did not differ between both groups. This can be attributed to the standard two team approach often utilized for autologous tissue reconstructions.

From an economic point of view, it is widely agreed upon that IBR is more cost-effective, as opposed to DBR [17, 41]. IBR involves less surgical procedures, thus recovery periods and hospitalization are reduced. In line with this, our data show significantly reduced hospitalization after IBR, as compared to DBR. Also, we found significantly earlier postoperative mobilization in the IBR group. In several surgical disciplines, early mobilization has been associated with a decrease of hospitalization, and thus health-related costs [42-44]. While the exact reasons for earlier mobilization in the IBR group remain unclear, these findings should further encourage IBR for the benefit of the patient, but also with regard to reducing health economic costs in times of rising economic pressure in healthcare. Despite being more 
Table 3 Postoperative complications over a follow-up period of 3 months

\begin{tabular}{llll}
\hline Postoperative complications & $\begin{array}{l}\text { Immediate } \\
\text { reconstruc- } \\
\text { tion }\end{array}$ & $\begin{array}{l}\text { Delayed } \\
\text { reconstruc- } \\
\text { tion }\end{array}$ & $p$ value \\
\hline Free flaps, $n$ & 1136 & 3441 & \\
Total flap loss $(n)$ & $26(2.3)$ & $66(1.9)$ & 0.516 \\
Partial flap loss $(n)$ & $11(1.0)$ & $40(1.2)$ & 0.706 \\
Revision surgery, $n(\%)$ & $88(7.7)$ & $337(9.8)$ & 0.039 \\
Venous thrombosis & $38(3.3)$ & $85(2.5)$ & 0.14 \\
Arterial thrombosis & $14(1.2)$ & $60(1.7)$ & 0.294 \\
Infection donor site & $2(0.2)$ & $21(0.6)$ & 0.12 \\
Infection recipient site & $2(0.2)$ & $18(0.5)$ & 0.201 \\
Hematoma donor site & $7(0.6)$ & $30(0.9)$ & 0.52 \\
Hematoma recipient site & $25(2.2)$ & $123(3.6)$ & 0.03 \\
Wound-healing disturbances requiring revision surgery, $n(\%)$ & \\
Donor site & $13(1.1)$ & $67(1.9)$ & 0.097 \\
Recipient site & $12(1.1)$ & $58(1.7)$ & 0.174 \\
Medical complications, $n(\%)$ & $75(6.6)$ & $219(6.4)$ & 0.777 \\
\hline
\end{tabular}

Percentages for each item are calculated based on the number of free flaps in each group

n, number

cost-effective, in our study, merely $25 \%$ of all DIEP reconstructions were performed immediately at the time of mastectomy. While only a hypothesis, we think this could be explained by the comparatively low reimbursement associated with IBR in Germany, ranging between $\sim 13.500 €$ for unilateral and $\sim 18.500 €$ for bilateral reconstruction [45]. However, a two-staged approach, i.e., a separation of mastectomy and reconstruction into two operative procedures and hospital stays, increases physicians' revenue.

The two groups were comparable with regard to age, mean BMI, the prevalence of comorbidities such as diabetes mellitus and coagulopathy, as well as nicotine abuse and immunosuppressive therapy prior to reconstruction. We did, however, observe significant differences with regard to chemotherapy and tamoxifen administration between both groups. Chemotherapeutic agents are cytotoxic and are thus considered to affect surgical outcome in breast reconstructions [46-48]. Perioperative tamoxifen therapy may increase the risk of thrombotic flap complications and flap loss [46, 49]. Our results show that patients in the IBR group received neoadjuvant chemotherapy significantly less frequently prior to reconstruction. In addition, although the difference was only marginal, patients in the IBR group received significantly less perioperative tamoxifen therapy. Thus, one may argue that patients in the DBR group were at significantly higher risk to develop postoperative complications, as compared to the IBR group. However, in patients that undergo mastectomy and IBR, recent studies found no increase in morbidity or complication rate with regard to neoadjuvant chemotherapy [47, 48]. Hence, one could interpret that the data points towards surgeons' prevailing reluctance to perform IBR after chemotherapy, although this may be unfounded.

In our study, we found significantly higher rates of bilateral breast reconstruction in the IBR group. Concordantly, this group showed higher rates of familial risk (defined as a pathogenic mutation identified in genetic test for familial/ hereditary breast cancer), higher rates of a positive family history for breast and/or ovarian cancer in FDRs, as well as a significantly higher genetic disposition for breast cancer. An increase in breast reconstructions has been described for patients desiring prophylactic mastectomies secondary to specific genetic mutations [11]. In accordance, the higher number of bilateral breast reconstructions in the IBR group could be related to a higher number of prophylactic contralateral mastectomies in conjunction with breast reconstruction in this group.

A significantly lower number of patients in the IBR group received neoadjuvant radiation therapy, as compared to the DBR group. Currently, the role of neoadjuvant radiation therapy and IBR is discussed as a feasible alternative as opposed to more traditional treatment concepts with a multimodal approach of chemotherapy, surgery, and postmastectomy radiotherapy [50, 51]. Ideal timing of breast reconstruction after radiation therapy is, however, controversially debated and further studies are needed in this regard [52-54].

A major strength of this study lies within the large sample size of 3926 female patients and 4577 DIEP flap breast reconstructions after malignancies in 22 different breast cancer centers. Patients were divided into two groups according to timing of reconstruction. We thus compared 1136 flaps for IBR with 3441 delayed free flaps. This series allows us to draw significant conclusions with regard to outcome and complications of DIEP tissue transfers for breast reconstruction depending on timing of reconstruction, and to our knowledge no previous study analyzed a series as large in this specific patient group.

Our data show significant differences within postoperative monitoring standards between both groups which arguably is a limiting factor of the study. This can be attributed to the multicenter nature of the study, since national standard operating procedures for free flap monitoring remain to be defined. Also, the indication for DIEP flap reconstructions differed between the groups. Unsurprisingly, the main reason for delayed DIEP reconstruction was status after mastectomy, while the primary reason for IBR was primary carcinoma. The inhomogeneity of both groups with regard to neoadjuvant chemo- and radiation therapy must also be considered a limitation of the study. Future studies must conduct multivariate analysis to account for confounding factors within the investigated groups. 


\section{Conclusion}

The presented study analyzed the largest series of microsurgical DIEP breast reconstructions in Europe, with regard to the timing of reconstruction. The data show that IBR is feasible and cannot be considered a risk factor for complications or flap outcome. Our results support the current trend towards increasing numbers of IBR. Especially in times of economic pressure in health care, the decrease in hospitalization associated with IBR cannot be overemphasized.

Authors' contribution LP: protocol/project development, data interpretation and analysis, manuscript writing/editing. NM: data interpretation and analysis, first draft manuscript writing/editing. UvF: conception of the study, manuscript writing/editing. RG: protocol/project development. GG: protocol/project development. AK: manuscript writing/editing. DL: manuscript writing/editing. FZ: data analysis, management and interpretation. PNB: manuscript writing/editing. PIH: conception of the study, data collection and management, data interpretation and analysis, first draft manuscript writing/editing.

Funding Open Access funding provided by Projekt DEAL.

\section{Compliance with ethical standards}

Conflict of interest The authors declare that they have no conflict of interest.

Ethics approval Ethical approval was obtained from the ethics commission of the Bavarian State Medical Association (156/17 S) and the Berlin Chamber of Physicians (Eth-V-Q/17). The study was performed in accordance with the ethical standards as laid down in the 1964 Declaration of Helsinki and its later amendments.

Ethical statement Ethical approval was obtained from the ethics commission of the Bavarian State Medical Association (156/17 S) and the Berlin Chamber of Physicians (Eth-V-Q/17). The study was performed in accordance with the ethical standards as laid down in the 1964 Declaration of Helsinki and its later amendments.

Open Access This article is licensed under a Creative Commons Attribution 4.0 International License, which permits use, sharing, adaptation, distribution and reproduction in any medium or format, as long as you give appropriate credit to the original author(s) and the source, provide a link to the Creative Commons licence, and indicate if changes were made. The images or other third party material in this article are included in the article's Creative Commons licence, unless indicated otherwise in a credit line to the material. If material is not included in the article's Creative Commons licence and your intended use is not permitted by statutory regulation or exceeds the permitted use, you will need to obtain permission directly from the copyright holder. To view a copy of this licence, visit http://creativecommons.org/licenses/by/4.0/.

\section{References}

1. Chen W, Lv X, Xu X, Gao X, Wang B (2018) Meta-analysis for psychological impact of breast reconstruction in patients with breast cancer. Breast Cancer 25(4):464-469. https://doi. org/10.1007/s12282-018-0846-8

2. Chao LF, Patel KM, Chen SC, Lam HB, Lin CY, Liu HE, Cheng MH (2014) Monitoring patient-centered outcomes through the progression of breast reconstruction: a multicentered prospective longitudinal evaluation. Breast Cancer Res Treat 146(2):299-308. https://doi.org/10.1007/s10549-014-3022-7

3. Ochoa O, Garza R 3rd, Pisano S, Chrysopoulo M, Ledoux P, Arishita G, Ketchum N, Michalek JE, Nastala C (2019) Prospective longitudinal patient-reported satisfaction and health-related quality of life following diep flap breast reconstruction: relationship with body mass index. Plast Reconstr Surg 143(6):15891600. https://doi.org/10.1097/PRS.0000000000005616

4. Al-Ghazal SK, Sully L, Fallowfield L, Blamey RW (2000) The psychological impact of immediate rather than delayed breast reconstruction. Eur J Surg Oncol 26(1):17-19. https://doi. org/10.1053/ejso.1999.0733

5. Elder EE, Brandberg Y, Bjorklund T, Rylander R, Lagergren J, Jurell G, Wickman M, Sandelin K (2005) Quality of life and patient satisfaction in breast cancer patients after immediate breast reconstruction: a prospective study. Breast 14(3):201208. https://doi.org/10.1016/j.breast.2004.10.008

6. Yoon AP, Qi J, Brown DL, Kim HM, Hamill JB, ErdmannSager J, Pusic AL, Wilkins EG (2018) Outcomes of immediate versus delayed breast reconstruction: results of a multicenter prospective study. Breast 37:72-79. https://doi.org/10.1016/j. breast.2017.10.009

7. Butler PD, Nelson JA, Fischer JP, Wink JD, Chang B, Fosnot J, Wu LC, Serletti JM (2016) Racial and age disparities persist in immediate breast reconstruction: an updated analysis of 48,564 patients from the 2005 to 2011 American College of Surgeons National Surgery Quality Improvement Program data sets. Am J Surg 212(1):96-101. https://doi.org/10.1016/j.amjsu rg.2015.08.025

8. Albornoz CR, Bach PB, Mehrara BJ, Disa JJ, Pusic AL, McCarthy CM, Cordeiro PG, Matros E (2013) A paradigm shift in U.S. Breast reconstruction: increasing implant rates. Plast Reconstr Surg 131(1):15-23. https://doi.org/10.1097/prs.0b013 e3182729cde

9. Park SH, Han W, Yoo TK, Lee HB, Jin US, Chang H, Minn KW, Noh DY (2016) Oncologic safety of immediate breast reconstruction for invasive breast cancer patients: a matched case control study. J Breast Cancer 19(1):68-75. https://doi. org/10.4048/jbc.2016.19.1.68

10. Patani N, Devalia H, Anderson A, Mokbel K (2008) Oncological safety and patient satisfaction with skin-sparing mastectomy and immediate breast reconstruction. Surg Oncol 17(2):97-105. https://doi.org/10.1016/j.suronc.2007.11.004

11. Panchal H, Matros E (2017) Current trends in postmastectomy breast reconstruction. Plast Reconstr Surg 140 (5S Advances in Breast Reconstruction). https://doi.org/10.1097/prs.0000000000 003941

12. Hu ES, Pusic AL, Waljee JF, Kuhn L, Hawley ST, Wilkins E, Alderman AK (2009) Patient-reported aesthetic satisfaction with breast reconstruction during the long-term survivorship Period. Plast Reconstr Surg 124(1):1-8. https://doi.org/10.1097/ PRS.0b013e3181ab10b2

13. Pusic AL, Matros E, Fine N, Buchel E, Gordillo GM, Hamill JB, Kim HM, Qi J, Albornoz C, Klassen AF, Wilkins EG (2017) Patient-reported outcomes 1 year after immediate breast reconstruction: results of the mastectomy reconstruction outcomes consortium study. J Clin Oncol 35(22):2499-2506. https://doi. org/10.1200/JCO.2016.69.9561

14. Yueh JH, Slavin SA, Adesiyun T, Nyame TT, Gautam S, Morris DJ, Tobias AM, Lee BT (2010) Patient satisfaction in postmastectomy breast reconstruction: a comparative evaluation of 
DIEP, TRAM, latissimus flap, and implant techniques. Plast Reconstr Surg 125(6):1585-1595. https://doi.org/10.1097/ PRS.0b013e3181cb6351

15. Healy C, Allen RJ Sr (2014) The evolution of perforator flap breast reconstruction: twenty years after the first DIEP flap. J Reconstr Microsurg 30(2):121-125. https://doi. org/10.1055/s-0033-1357272

16. Chang DW (2012) Breast reconstruction with microvascular MS-TRAM and DIEP flaps. Arch Plast Surg 39(1):3-10. https ://doi.org/10.5999/aps.2012.39.1.3

17. Neyt MJ, Blondeel PN, Morrison CM, Albrecht JA (2005) Comparing the cost of delayed and immediate autologous breast reconstruction in Belgium. Br J Plast Surg 58(4):493-497. https ://doi.org/10.1016/j.bjps.2004.12.002

18. Wilkins EG, Cederna PS, Lowery JC, Davis JA, Kim HM, Roth RS, Goldfarb S, Izenberg PH, Houin HP, Shaheen KW (2000) Prospective analysis of psychosocial outcomes in breast reconstruction: one-year postoperative results from the Michigan Breast Reconstruction Outcome Study. Plast Reconstr Surg 106(5):1014 1025. https://doi.org/10.1097/00006534-200010000-00010 (discussion 1026-1017)

19. O'Connell RL, Di Micco R, Khabra K, Kirby AM, Harris PA, James SE, Power K, Ramsey KWD, Rusby JE (2018) Comparison of immediate versus delayed DIEP flap reconstruction in women who require postmastectomy radiotherapy. Plast Reconstr Surg 142(3):594-605. https://doi.org/10.1097/PRS.0000000000004676

20. Khajuria A, Charles WN, Prokopenko M, Beswick A, Pusic AL, Mosahebi A, Dodwell DJ, Winters ZE (2020) Immediate and delayed autologous abdominal microvascular flap breast reconstruction in patients receiving adjuvant, neoadjuvant or no radiotherapy: a meta-analysis of clinical and quality-of-life outcomes. BJS Open 4(2):182-196. https://doi.org/10.1002/bjs5.50245

21. Beugels J, Bod L, van Kuijk SMJ, Qiu SS, Tuinder SMH, Heuts EM, Piatkowski A, van der Hulst R (2018) Complications following immediate compared to delayed deep inferior epigastric artery perforator flap breast reconstructions. Breast Cancer Res Treat 169(2):349-357. https://doi.org/10.1007/s10549-018-4695-0

22. Fritschen UV, Grill B, Wagner J, Schuster H, Sukhova I, Giunta RE, Heitmann C, Andree C, Horch RE, Kneser U, Germann G (2019) Quality assurance in breast reconstruction-establishment of a prospective national online registry for microsurgical breast reconstructions. Handchir Mikrochir Plast Chir. https://doi. org/10.1055/a-1075-2525

23. Prantl L, Moellhoff N, Fritschen UV, Germann G, Giunta RE, Zeman F, Kehrer A, Lonic D, Broer PN, Ehrl D, Heidekrueger PI (2020) Impact of smoking status in free deep inferior epigastric artery perforator flap breast reconstruction: a multicenter study. $\mathbf{J}$ Reconstr Microsurg. https://doi.org/10.1055/s-0040-1714426

24. Agrawal A, Grewal M, Sibbering DM, Courtney CA (2013) Surgical and oncological outcome after skin-sparing mastectomy and immediate breast reconstruction. Clin Breast Cancer 13(6):478481. https://doi.org/10.1016/j.clbc.2013.08.013

25. Agrawal A, Sibbering DM, Courtney CA (2013) Skin sparing mastectomy and immediate breast reconstruction: a review. Eur J Surg Oncol 39(4):320-328. https://doi.org/10.1016/j. ejso.2012.12.015

26. Nedumpara T, Jonker L, Williams MR (2011) Impact of immediate breast reconstruction on breast cancer recurrence and survival. Breast 20(5):437-443. https://doi.org/10.1016/j.breas t.2011.04.006

27. Frey JD, Choi M, Salibian AA, Karp NS (2017) Comparison of outcomes with tissue expander, immediate implant, and autologous breast reconstruction in greater than 1000 nipple-sparing mastectomies. Plast Reconstr Surg 139(6):1300-1310. https://doi. org/10.1097/PRS.0000000000003340
28. Fujimoto H, Ishikawa T, Satake T, Ko S, Shimizu D, Narui K, Yamada A, Sasaki T, Nagashima T, Endo I, Miyazaki M (2016) Donor site selection and clinical outcomes of nipple-areola skin-sparing mastectomy with immediate autologous free flap reconstruction: a single-institution experience. Eur J Surg Oncol 42(3):369-375. https://doi.org/10.1016/j.ejso.2015.12.002

29. Levine SM, Snider C, Gerald G, Tanna N, Broer PN, Stolier A, Sadeghi A, Allen RJ Sr (2013) Buried flap reconstruction after nipple-sparing mastectomy: advancing toward single-stage breast reconstruction. Plast Reconstr Surg 132(4):489e-497e. https://doi. org/10.1097/PRS.0b013e3182a00e79

30. Sgarzani R, Negosanti L, Morselli PG, Vietti Michelina V, Lapalorcia LM, Cipriani R (2015) Patient satisfaction and quality of life in DIEAP flap versus implant breast reconstruction. Surg Res Pract 2015:405163. https://doi.org/10.1155/2015/405163

31. Rosenqvist S, Sandelin K, Wickman M (1996) Patients' psychological and cosmetic experience after immediate breast reconstruction. Eur J Surg Oncol 22(3):262-266. https://doi. org/10.1016/s0748-7983(96)80015-1

32. Heimes AS, Stewen K, Hasenburg A (2017) Psychosocial aspects of immediate versus delayed breast reconstruction. Breast Care (Basel) 12(6):374-377. https://doi.org/10.1159/000485234

33. Alderman AK, Storey AF, Nair NS, Chung KC (2009) Financial impact of breast reconstruction on an academic surgical practice. Plast Reconstr Surg 123(5):1408-1413. https://doi.org/10.1097/ PRS.0b013e3181a0722d

34. Sheckter CC, Yi D, Panchal HJ, Razdan SN, Pusic AL, McCarthy CM, Cordeiro PG, Disa JJ, Mehrara B, Matros E (2018) Trends in physician payments for breast reconstruction. Plast Reconstr Surg 141(4):493e-499e. https://doi.org/10.1097/PRS.0000000000 004205

35. Sheckter CC, Panchal HJ, Razdan SN, Rubin D, Yi D, Disa JJ, Mehrara B, Matros E (2018) The influence of physician payments on the method of breast reconstruction: a national claims analysis. Plast Reconstr Surg 142(4):434e-442e. https://doi.org/10.1097/ PRS.0000000000004727

36. Sanati-Mehrizy P, Massenburg BB, Rozehnal JM, Gupta N, Rosa JH, Ingargiola MJ, Taub PJ (2015) A comparison of postoperative outcomes in immediate versus delayed reconstruction after mastectomy. Eplasty 15:e44

37. Fischer JP, Wes AM, Tuggle CT, Wu LC (2014) Venous thromboembolism risk in mastectomy and immediate breast reconstruction: analysis of the 2005 to 2011 American College of Surgeons National Surgical Quality Improvement Program data sets. Plast Reconstr Surg 133(3):263e-273e. https://doi.org/10.1097/01. prs.0000438062.53914.22

38. Fischer JP, Tuggle CT, Au A, Kovach SJ (2014) A 30-day risk assessment of mastectomy alone compared to immediate breast reconstruction (IBR). J Plast Surg Hand Surg 48(3):209-215. https ://doi.org/10.3109/2000656X.2013.865633

39. D'Souza N, Darmanin G, Fedorowicz Z (2011) Immediate versus delayed reconstruction following surgery for breast cancer. Cochrane Database Syst Rev. https://doi.org/10.1002/14651858. cd008674.pub2

40. Robinson DW (1983) The hazards of surgery in irradiated tissue. Ann Plast Surg 11(1):74-82. https://doi.org/10.1097/00000637198307000-00013

41. Khoo A, Kroll SS, Reece GP, Miller MJ, Evans GR, Robb GL, Baldwin BJ, Wang BG, Schusterman MA (1998) A comparison of resource costs of immediate and delayed breast reconstruction. Plast Reconstr Surg 101(4):964-968. https://doi. org/10.1097/00006534-199804040-00011 (discussion 969-970)

42. Okamoto T, Ridley RJ, Edmondston SJ, Visser M, Headford J, Yates PJ (2016) Day-of-surgery mobilization reduces the length of stay after elective hip arthroplasty. J Arthroplasty 31(10):22272230. https://doi.org/10.1016/j.arth.2016.03.066 
43. Yakkanti RR, Miller AJ, Smith LS, Feher AW, Mont MA, Malkani AL (2019) Impact of early mobilization on length of stay after primary total knee arthroplasty. Ann Transl Med 7(4):69. https:// doi.org/10.21037/atm.2019.02.02

44. Kates SL, Shields E, Behrend C, Noyes KK (2015) Financial implications of hospital readmission after hip fracture. Geriatr Orthop Surg Rehabil 6(3):140-146. https://doi.org/10.1177/21514 58515578265

45. Bergmeister KD, Fansa H, Lehnhardt M, Djedovic G, Harder Y, Schaefer DJ, Vogt PM (2019) Profitability of reconstructive microsurgery: position paper of the German-Speaking Group for Microsurgery of Peripheral Nerves and Vessels. Handchir Mikrochir Plast Chir 51(6):418-423. https://doi.org/10.1055/a-0987-0266

46. Decker MR, Greenblatt DY, Havlena J, Wilke LG, Greenberg CC, Neuman HB (2012) Impact of neoadjuvant chemotherapy on wound complications after breast surgery. Surgery 152(3):382388. https://doi.org/10.1016/j.surg.2012.05.001

47. Song J, Zhang X, Liu Q, Peng J, Liang X, Shen Y, Liu H, Li H (2014) Impact of neoadjuvant chemotherapy on immediate breast reconstruction: a meta-analysis. PLoS ONE 9(5):e98225. https:// doi.org/10.1371/journal.pone.0098225

48. Monrigal E, Dauplat J, Gimbergues P, Le Bouedec G, Peyronie M, Achard JL, Chollet P, Mouret-Reynier MA, Nabholtz JM, Pomel C (2011) Mastectomy with immediate breast reconstruction after neoadjuvant chemotherapy and radiation therapy. A new option for patients with operable invasive breast cancer. Results of a 20 years single institution study. Eur J Surg Oncol 37(10):864870. https://doi.org/10.1016/j.ejso.2011.07.009

49. Kelley BP, Valero V, Yi M, Kronowitz SJ (2012) Tamoxifen increases the risk of microvascular flap complications in patients undergoing microvascular breast reconstruction. Plast Reconstr
Surg 129(2):305-314. https://doi.org/10.1097/PRS.0b013e3182 $3 \mathrm{ae} 86 \mathrm{c}$

50. Hughes K, Neoh D (2018) Neoadjuvant radiotherapy: changing the treatment sequence to allow immediate free autologous breast reconstruction. J Reconstr Microsurg 34(8):624-631. https://doi. org/10.1055/s-0038-1660871

51. Singh P, Hoffman K, Schaverien MV, Krause KJ, Butler C, Smith BD, Kuerer HM (2019) Neoadjuvant radiotherapy to facilitate immediate breast reconstruction: a systematic review and current clinical trials. Ann Surg Oncol 26(10):3312-3320. https://doi. org/10.1245/s10434-019-07538-x

52. Kronowitz SJ (2010) Delayed-immediate breast reconstruction: technical and timing considerations. Plast Reconstr Surg 125(2):463-474. https://doi.org/10.1097/PRS.0b013e3181c82d58

53. Baumann DP, Crosby MA, Selber JC, Garvey PB, Sacks JM, Adelman DM, Villa MT, Feng L, Robb GL (2011) Optimal timing of delayed free lower abdominal flap breast reconstruction after postmastectomy radiation therapy. Plast Reconstr Surg 127(3):1100-1106. https://doi.org/10.1097/PRS.0b013e3182 043652

54. Momoh AO, Colakoglu S, de Blacam C, Gautam S, Tobias AM, Lee BT (2012) Delayed autologous breast reconstruction after postmastectomy radiation therapy: is there an optimal time? Ann Plast Surg 69(1):14-18. https://doi.org/10.1097/SAP.0b013e3182 1 ee4b6

Publisher's Note Springer Nature remains neutral with regard to jurisdictional claims in published maps and institutional affiliations. 